Julie Novkov, University of Michigan

Eric Ziegelmayer, SUNY-Albany

The APSA Advanced Graduate Student Travel Grant Program was established in 1994 to enable graduate students to attend the annual meeting. The need for such a program is evident given the decline in department travel funds and the increase in the numbers of graduate students presenting papers. The APSA urges its members to support this effort by contributing to the Travel Grant Program. If you would like to contribute to the Program, please make checks payable to "APSA Travel" and send to the APSA National Office, 1527 New Hampshire Ave., NW, Washington, DC 20036.

\section{Annual Meeting Short Courses Provide Diverse Professional Development Opportunities}

This year's Annual Meeting featured 14 short courses to inaugurate the meeting's Wednesday pre-session. A variety of APSA Organized Sections and related organizations sponsored the short courses, which provided nearly 100 early attendees with forums for professional development targeted to their particular interests and fields.

This year's Leading Scholars Series featured Elinor Ostrom, APSA President-Elect and Co-Director of the Workshop in Political Theory and Policy Analysis at Indiana University, and Vincent Ostrom, CoDirector of the Workshop in Political Theory and Policy Analysis. As in the past, the Leading Scholar Series served as a cost-free opportunity for graduate staudents to participate in an informal session with prominent scholars in the profession. The series emphasized the evolution of the leaders' intellectual and professional agendas and scholarship.

In addition to the Leading Scholar Series, short courses explored is- sues such as race and political development, and cultural perspectives on the 1994 election which related to the Annual Meeting's theme, Liberalism at Century's End: Competing Perspectives. Beyond topics directly representing the theme, some sessions also focused on diverse issues such as the role of technology in the profession, a retrospective assessment of nuclear proliferation since Hiroshima, and teaching and professional development methods.

One workshop on foreign policy and opinion polling conducted a straw poll of more than 250 participants on United States foreign policy toward Bosnia. The survey, sponsored by the Section on Domestic Sources of Foreign Policy and the Chicago Council on Foreign Relations, found widespread support in theory for a continuation of current policies, with isolated groups advocating significant policy shifts. Respondents identified two goals for United States Bosnia policy, the primary being humanitarian and the secondary being a concern for regional, and not necessarily United States, security. Survey results bolstered Chicago Council findings indicating elites support the use of force more than the general public.

\section{Report of the Managing Editor of the American Political Science Review, August 30, 1995}

\section{G. Bingham Powell, Jr., University of Rochester}

Being editor of the American Political Science Review is, as I have frequently remarked, the best job in the world-except that there's just a bit too much of it. The job is fascinating, diverse, challenging, worthy, well respected by one's peers (usually) and seldom involves a committee meeting. What more could one want? More hours in the day, perhaps, or the absence of other responsibilities, especially at exam time, when convergent editorial and university deadlines can overwhelm the editor's system. A one-month moratorium to break up the relentless flow of two-plus manuscripts a day for 52 weeks a year would be nice. Referee reports that appeared on time would be a dream. But, overall, it's a wonderful job "as is." I am grateful to the Association for allowing me to hold it for four years.

Of course, for the "decisionally challenged" such as I, who have been known to agonize for an hour over giving an undergraduate paper a $\mathrm{B}+$ or $\mathrm{A}-$, each decision takes its toll. Small wonder that after 2,000 of them (not counting referee choices), I am glad to pass along the responsibility to fresh shoulders. After very hard work on both sides and close cooperation between Ada Finifter and me, as well as the old Rochester and new Michigan State associate editors, the transition of $A P S R$ editors is nearly complete. I am very grateful to Ada Finifter for facilitating the transition by undertaking so much hard work before her term officially begins; I am confident she will reap the rewards of these initial efforts in the years to come. I leave APSR exhausted, feeling that I have done all that I could do, but not without regret.

\section{The Cumulative Statistical Record}

Between July 1, 1991, and June 30,1995 , nearly 2,000 manuscripts were submitted to the APSR. Table 1 shows the distributions of these across the five standard subfields. These total 1,941 manuscripts. Another 25 manuscripts or so that were received are not shown because they could not be classified as political science. Of the 1,941 political science manuscripts, some 216 were revisions of previously submitted manuscripts, while the other 1,725 were completely new submissions. About 100 of these new submissions were rejected without review, frequently for excessive length; a number of these reappeared in the "revised" group in briefer form.

The other $1,600+$ received the standard procedure that we developed in our first few months of operation. They were logged in and assigned to an APSR graduate stu- 